\title{
In Vivo and In Vitro Effects of Human Growth Hormone on Rat Intestinal Ion Transport
}

\author{
ALFREDO GUARINO, ROBERTO BERNI CANANI, MICHELE IAFUSCO, ANTONELLA CASOLA, \\ ROSARIO RUSSO, AND ARMIDO RUBINO
}

Department of Pediatrics, University "Federico II," Naples, Italy \begin{abstract}
It has been reported that: 1 ) ovine growth hormone stimulates
intestinal water, sodium, and chloride absorption and 2) specific growth hormone receptors are present in the rat intestine. Aims of this work were to investigate the effects of acute administration of hGH on water and ion transport in the rat ileum in vivo and in vitro. In vivo, the absorption rates of water, sodium, chloride, and potassium were determined in the rat perfused ileum, during a basal period and after i.v. administration of 6 $\mu \mathrm{g} / \mathrm{kg}$ recombinant DNA-derived hGH. In vitro, electrical parameters were measured before and after the hormone addition to the mucosal or the serosal side of rat ileal mucosa mounted in Ussing chambers. In vivo, growth hormone induced a rapid increase in the absorption rates of water, sodium, chloride, and potassium. In vitro, the serosal, but not the mucosal, addition of growth hormone induced a rapid decrease of transepithelial potential difference and of short-circuit current. The effect was time- and dose-dependent, saturable, but not reversible in the short time. The electrical effect was abolished in the absence of
\end{abstract}

chloride, indicating that it was related, at least in part, to inhibition of basal active chloride secretion. Growth hormone also reduced the short-circuit current increase induced by the secretagogues Escherichia coli heat-stable enterotoxin, theophylline, and calcium ionophore A23187. These results indicate that hGH has a rapid absorptive effect that is related, at least in part, to a direct intestinal antisecretory mechanism. It also reduces active intestinal secretion induced by various secretagogues. (Pediatr Res 37: 576-580, 1995)
GH, growth hormone
Abbreviations
r-hGH, recombinant DNA-derived hGH
Isc, short-circuit current
PD, transepithelial potential difference
$\mathbf{G}$, tissue conductance
ST, Escherichia coli heat-stable enterotoxin

The ability of GH to induce fluid retention is well established, but the mechanisms of this effect are not well understood (1). Most studies have focused on the interrelationships between various hormones taking part to the complex network that regulates $\mathrm{Na}^{+}$balance and on the renal effects of $\mathrm{GH}(1)$.

It is now known that the intestine plays an important role in the regulation of body fluid homeostasis (2). GH has several effects at the intestinal level. In fact, it stimulates intestinal growth and differentiation $(3,4)$, vitamin D-dependent $\mathrm{Ca}^{2+}$ binding protein synthesis (5), and $\mathrm{Ca}^{2+}$ absorption (6). Furthermore, GH increases the gastrin and somatostatin contents of rat stomach (7). Finally, it has been previously shown that high doses of ovine $\mathrm{GH}$, given to rats for $2 \mathrm{~d}$ in vivo, increased the absorption rates of $\mathrm{H}_{2} \mathrm{O}$ and electrolytes as measured by intestinal everted sacs (8). The effects of $\mathrm{GH}$ have been tradi-

\footnotetext{
Received March 8, 1994; accepted November 14, 1994.

Correspondence: Alfredo Guarino, M.D., Department of Pediatrics, University of Naples, Via S. Pansini, 5, 80131, Naples, Italy.

This work was supported in part by a grant from Consiglio Nazionale Ricerche Target Project "Biotechnology and Bioinstrumentation," research program 91.01231. P.F. 70, by a grant from Ministero della Sanità, AIDS research project (1993), program 9205-22 and by a grant from FATMA N. 92/00170P.F.41, Subproject "Disease factors in maternal infantile pathology."
}

tionally believed to be mediated by GH-dependent production of mediators such as IGF-I $(9,10)$. However, it has been reported that IGF-I does not cause fluid retention (11). Recently GH has been shown to inhibit the production of the atrial natriuretic peptide (12). Inasmuch as atrial natriuretic peptide is capable of directly inducing $\mathrm{H}_{2} \mathrm{O}$ and electrolyte secretion in the rat intestine (13), the inhibition of its production could be an indirect mechanism of a proabsorptive effect by $\mathrm{GH}$.

However, the recently reported evidence of $\mathrm{GH}$ receptors in the rat gastrointestinal tract (14) raises the hypothesis that $\mathrm{GH}$ exerts its effect through a direct mechanism. We have investigated the effects of $\mathrm{GH}$ administration on intestinal $\mathrm{H}_{2} \mathrm{O}$ and electrolyte transport in vivo by the rat perfused intestine and in vitro by exposing the isolated intestine to the hormone and studying its electrical parameters, which reflect the modifications of transepithelial ion transport.

\section{METHODS}

Animals. Wistar male rats, weighing 230-280 g and fed Purina Rat Chow (Ralston-Purina, St. Louis, MO), were starved for $12 \mathrm{~h}$ before the experiments, but allowed tap water ad libitum. 
In vivo intestinal perfusion. On the day of the experiment, the animal was anesthetized with intraperitoneal sodium thiopental $(6.25 \mathrm{mg} / 100 \mathrm{~g}$ of body weight). The rectal temperature was maintained at $37^{\circ} \mathrm{C}$ throughout the experiment by overhead electric lamps. The abdomen was opened with a midline incision and a 10- to $20-\mathrm{cm}$ segment of distal ileum was prepared. Fecal material was removed from the loop by washing with isotonic saline at $37^{\circ} \mathrm{C}$. Influx and efflux catheters were placed into the loop, which was perfused at a constant rate of $0.2 \mathrm{~mL} / \mathrm{min}$. Perfusion fluid consisted of (in $\mathrm{mmol} / \mathrm{L}$ ): $\mathrm{NaCl} 115, \mathrm{NaHCO}_{3} 25, \mathrm{~K}_{2} \mathrm{HPO}_{4} 2.4, \mathrm{KH}_{2} \mathrm{PO}_{4} 0.4, \mathrm{CaCl}_{2} 1.2$, and mannitol to a final osmolality of $290 \mathrm{mosmol} / \mathrm{kg}$, [14C] polyethylene glycol (molecular weight 4000), and unlabeled polyethylene glycol $3 \mathrm{~g} / \mathrm{L}$, as a nonabsorbable water marker. Recoveries of polyethylene glycol ranged from 95 to $105 \%$. The $\mathrm{pH}$ was maintained at 7.4 by gassing with $95 \% \mathrm{O}_{2}-5 \%$ $\mathrm{CO}_{2}$.

Each experiment lasted $120 \mathrm{~min}$ and consisted of two periods. The first was a 60 -min equilibration period, during which perfusate was collected for three consecutive 20-min periods to establish baseline values of $\mathrm{H}_{2} \mathrm{O}, \mathrm{Na}^{+}, \mathrm{Cl}^{-}$, and $\mathrm{K}^{+}$, as previously described (15). The second 60 -min period was started by giving $\mathrm{GH}$ in the form of recombinant DNA-derived human GH (r-hGH), as a bolus of $6 \mu \mathrm{g} / \mathrm{kg}$ of body weight in $150 \mu \mathrm{L}$ of saline solution by the i.v. route. Intestinal effluent was collected for three consecutive 20-min periods to determine the absorption rates upon stimulation with r-hGH. Control animals received r-hGH-free saline solution.

The rats were killed at the end of the experiment, and the loops were dissected, stripped of mesentery, and weighed. The collected samples were analyzed, as previously described (15), for $\mathrm{Na}^{+}$and $\mathrm{K}^{+}$content by flame photometer (Instrumentation Laboratory 243, ILSUD SpA, Ascoli Piceno, Italy), for $\mathrm{Cl}^{-}$by a chloride analyzer (Corning 926, Corning Ltd., Halstead, Essex, UK), and for polyethylene glycol by liquid scintillation analyzer (Packard 1600 TR, Packard Instrument Co., Downers Grove, IL).

Ussing chamber studies. Animals were killed by cervical dislocation. Four paired fragments of rat ileal unstripped mucosa were mounted in Ussing chambers containing Ringer's solution, as previously described (16). The bathing solution had the following composition (in mmol/L): $\mathrm{NaCl} 53, \mathrm{KCl} 5, \mathrm{Na}_{2} \mathrm{SO}_{4} 30.5$, mannitol 30.5, $\mathrm{Na}_{2} \mathrm{HPO}_{4}$ 1.69, $\mathrm{NaH}_{2} \mathrm{PO}_{4} 0.3, \mathrm{CaCl}_{2} 1.25, \mathrm{MgCl}_{2}$ 1.1 , and $\mathrm{NaHCO}_{3} 25$. It was maintained at $37^{\circ} \mathrm{C}$ with waterjacketed reservoirs connected to a thermostated circulating pump and constantly gassed with $95 \% \mathrm{O}_{2}-5 \% \mathrm{CO}_{2}$. $\mathrm{PD}$, Isc, and $\mathrm{G}$ were measured as previously described (16), before and after the mucosal or serosal addition of various doses (ranging from 2 to 400 $\mathrm{ng} / \mathrm{mL}$, i.e. $10^{-7}$ to $8 \times 10^{-6} \mathrm{M}$ ) of $\mathrm{r}-\mathrm{hGH}$. Control tissues were treated with the same volumes of r-hGH-free Ringer's solution. Variations between baseline electrical parameters of tissues mounted in the Ussing chamber did not exceed $10 \%$. In the experiments performed to study the reversibility of r-hGH effect, the hormone-containing Ringer's solution was rapidly removed from the chamber and substituted by r-hGH-free Ringer's solution. To test the role of $\mathrm{Cl}^{-}$in the effects of $\mathrm{r}-\mathrm{hGH}$, experiments were performed in $\mathrm{Cl}^{-}$-free Ringer's solution. In these experiments $\mathrm{Cl}^{-}$was replaced by an equimolar concentration of $\mathrm{SO}_{4}^{2-}$.
The viability of intestinal specimens mounted in each Ussing chamber was checked at the end of each experiment by adding $10 \mathrm{mmol}$ of glucose/L to the mucosal side to obtain an Isc response. In cases in which this was less than $50 \%$ of that of controls at 0 time, the result was not considered.

To investigate the effects of r-hGH on active intestinal secretion, secretion was induced by ST, theophylline, or the $\mathrm{Ca}^{2+}$ ionophore A23187 (17). In these experiments, intestinal tissues were incubated with $\mathrm{r}-\mathrm{hGH}$ (at a final concentration of $4 \times 10^{-6} \mathrm{M}$ ); $20 \mathrm{~min}$ later the secretagogue to be tested was added, and the resulting peak increments of Isc were recorded in the next $60 \mathrm{~min}$. Each secretagogue was used at its maximally effective concentration, as determined in prior doseresponse studies (18). ST was added to the mucosal side at the final concentration of $10^{-7} \mathrm{M}$. Theophylline was added to the serosal side at the final concentration of $5 \times 10^{-3} \mathrm{M} . \mathrm{Ca}^{2+}$ ionophore A23187 was added to the serosal side at the concentration of $5 \times 10^{-7} \mathrm{M}$. Control tissues were either those not pretreated with r-hGH but exposed to the same concentration of each of the secretagogues used or those receiving r-hGH only.

The research project was approved by the Ethical Committee of the 2nd School of Medicine, University Federico II of Naples.

Chemicals. $\mathrm{r}-\mathrm{hGH}$ was obtained from Serono (Industria farmaceutica Serono, Rome, Italy). All chemicals were of reagent grade and were purchased from Sigma Chemical Co. (St. Louis, MO).

Statistics. Each experiment was performed at least three times. Results are expressed as means \pm SEM. Results of perfusion studies are expressed as microliters of $\mathrm{H}_{2} \mathrm{O}$ or microequivalents of electrolyte $\cdot \mathrm{min} \cdot \mathrm{g}$ of wet tissue weight. Results of Ussing chamber studies are expressed as follows: Isc as $\mu \mathrm{A} / \mathrm{cm}^{2}, \mathrm{G}$ as $\mathrm{mS} / \mathrm{cm}^{2}$, and PD as $\mathrm{mV}$. Isc values of doseresponse experiments and of those investigating the effects of secretagogues are expressed as the difference of Isc between basal and stimulated tissues. The significance of the differences was calculated using the $t$ test for paired data.

\section{RESULTS}

Effects of $r$-hGH in the in vivo perfused ileum. Net fluxes of $\mathrm{H}_{2} \mathrm{O}$ and electrolytes during in vivo perfusion in experimental and control animals are shown in Figure 1. There were no differences in the absorption rates of $\mathrm{H}_{2} \mathrm{O}$ (Fig. $1 A$ ), $\mathrm{Na}^{+}$(Fig. $1 B$ ), $\mathrm{Cl}^{-}$(Fig. $1 C$ ), and $\mathrm{K}^{+}$(Fig. $1 D$ ) between the two groups during the equilibration period $(0-60 \mathrm{~min})$. In control animals the absorptive pattern did not change in period 2, whereas in animals receiving i.v. administration of $\mathrm{r}-\mathrm{hGH}$, a significant increase in $\mathrm{H}_{2} \mathrm{O}$ absorption was observed (Fig. 1A). The effect was prompt, reaching its peak within 20 min from administration of $\mathrm{r}-\mathrm{hGH}$ and then slowly declining toward baseline levels. However, the difference between animals receiving r-hGH and controls maintained its statistical significance throughout the duration of the experiment (Fig. 1). The pattern of absorption of $\mathrm{Na}^{+}$(Fig. 1B), $\mathrm{Cl}^{-}$(Fig. 1C), and $\mathrm{K}^{+}$(Fig. 1D) paralleled that of $\mathrm{H}_{2} \mathrm{O}$. 

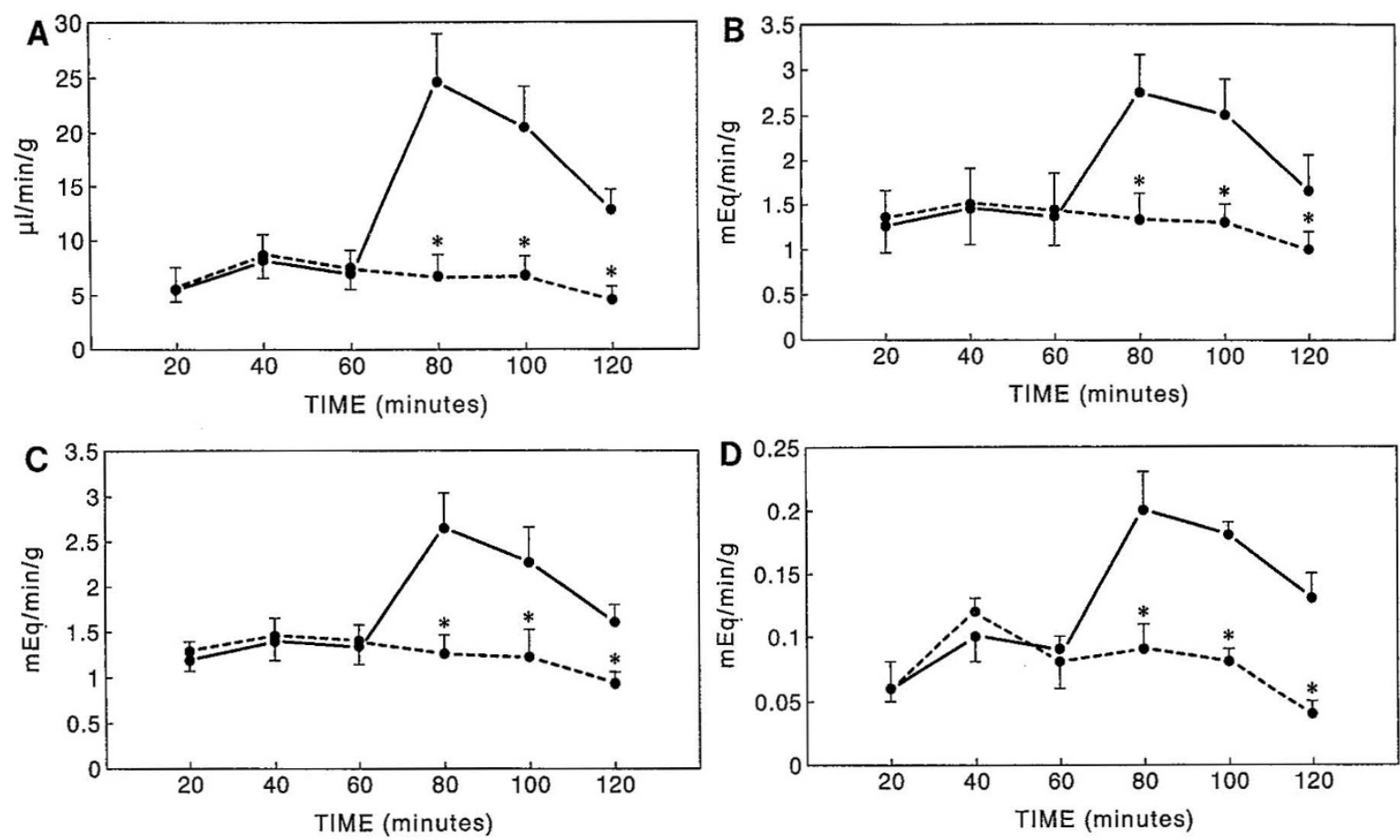

Figure 1. Effect of $\mathrm{r}-\mathrm{hGH}$ on in vivo ileal absorption of $\mathrm{H}_{2} \mathrm{O}(A), \mathrm{Na}^{+}(B), \mathrm{Cl}^{-}(C)$, and $\mathrm{K}^{+}(D)$. After 60 min of equilibration $\mathrm{r}-\mathrm{hGH}(6 \mu \mathrm{g} / \mathrm{kg})$ was administered by i.v. route (continuous line), and absorption rates were determined each $20 \mathrm{~min}$. Control animals (dotted line) received r-hGH-free saline solution. ${ }^{*} p<0.01$ $(n=15)$.

Effects of $r$-hGH in the in vitro ileal mucosa mounted in Ussing chambers. The mucosal addition of r-hGH did not induce modifications of electrical parameters. The serosal addition of r-hGH induced a rapid fall in Isc. Isc decrease was time-dependent, reaching its maximum in $40 \mathrm{~min}$ and remaining stable thereafter (Fig. 2). The serosal effect was entirely due to a decrease of PD, because no modifications of $G$ values were observed (Fig. 2).

To determine whether the effect of r-hGH was dosedependent, increasing amounts of $\mathrm{r}$-hGH were added to the serosal side of rat ileal specimens mounted in Ussing chambers, and Isc values were recorded after $60 \mathrm{~min}$ of incubation with each dose. Results are shown in Figure 3. The r-hGHinduced decrease of Isc was dose-dependent, and the calculated

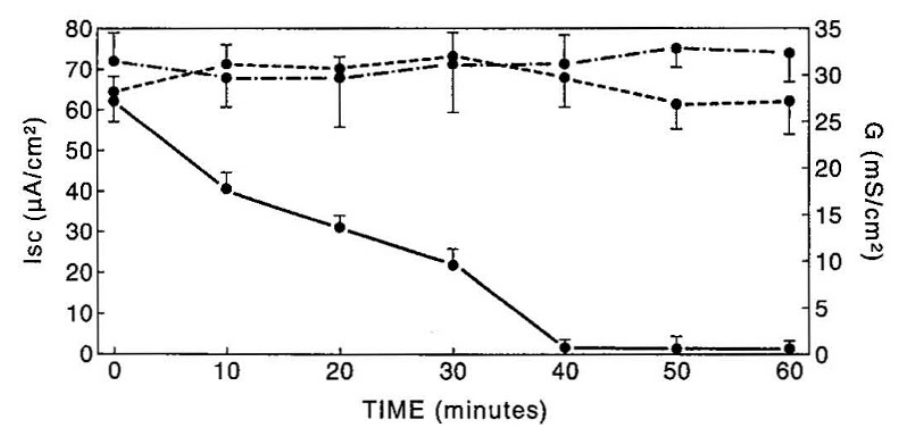

Figure 2. Time course effect of $\mathrm{r}-\mathrm{hGH}$ on Isc and $\mathrm{G}$ in rat ileal mucosa mounted in Ussing chambers. $\mathrm{r}-\mathrm{hGH}$ was added at 0 time $(n=6)$. (-) Isc of tissues treated with $4 \times 10^{-6} \mathrm{M} \mathrm{r}-\mathrm{hGH}$ to the serosal side (Isc scale is expressed as $\mu \mathrm{A} / \mathrm{cm}^{2}$ on the left side of the figure). (-...) Isc of tissues treated with $4 \times 10^{-6} \mathrm{M} \mathrm{r}$-hGH to the mucosal side. (--) $\mathrm{G}$ of tissues receiving $\mathrm{r}-\mathrm{hGH}$ to serosal side ( $\mathrm{G}$ scale is expressed as $\mathrm{mS} / \mathrm{cm}^{2}$ on the right side of the figure). half-maximal effect was achieved with $10^{-6} \mathrm{M}$ or $50 \mathrm{ng} / \mathrm{mL}$ $\mathrm{r}$-hGH. Concentrations higher than $4 \times 10^{-6} \mathrm{M} \mathrm{r}-\mathrm{hGH}$ did not induce any further decrease of Isc, indicating a saturation pattern of the effect.

Lack of reversibility of $\boldsymbol{r}$-hGH effect. To determine whether $\mathrm{r}$-hGH effect was reversible, intestinal tissue was incubated in the presence of the hormone for $35 \mathrm{~min}$. r-hGH-containing Ringer's solution was then rapidly removed from the Ussing chamber, and the tissue was washed twice and rapidly reincubated with r-hGH-free Ringer's solution. Results are reported in Figure 4.

A slight rise in Isc was observed shortly after removal of $\mathrm{r}$-hGH. However, no significant difference with Isc of tissues constantly exposed to $\mathrm{r}-\mathrm{hGH}$ was observed.

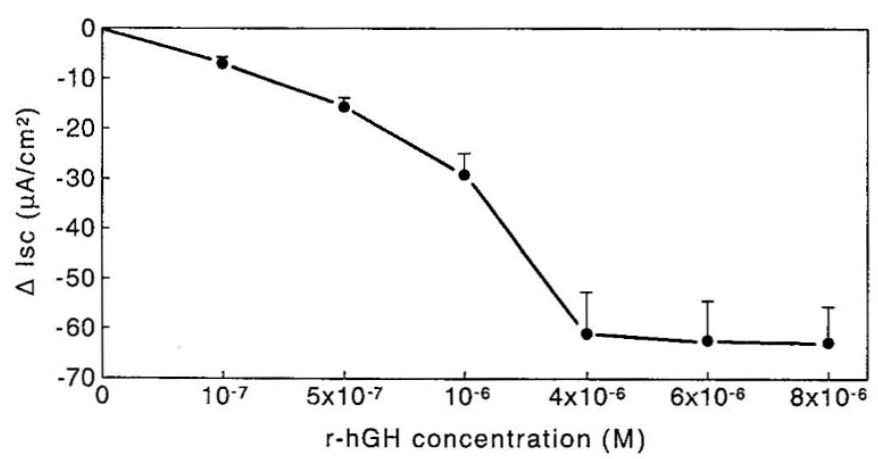

Figure 3. Dose-response of Isc to r-hGH administration. Each dose was administered to a single intestinal specimen mounted in Ussing chamber, and Isc was recorded $60 \mathrm{~min}$ after hormone addition. The effect is reported as the difference between baseline Isc and hormone-stimulated Isc. Half-maximal effect was achieved with $10^{-6} \mathrm{M}(n=5$ for each data point). 


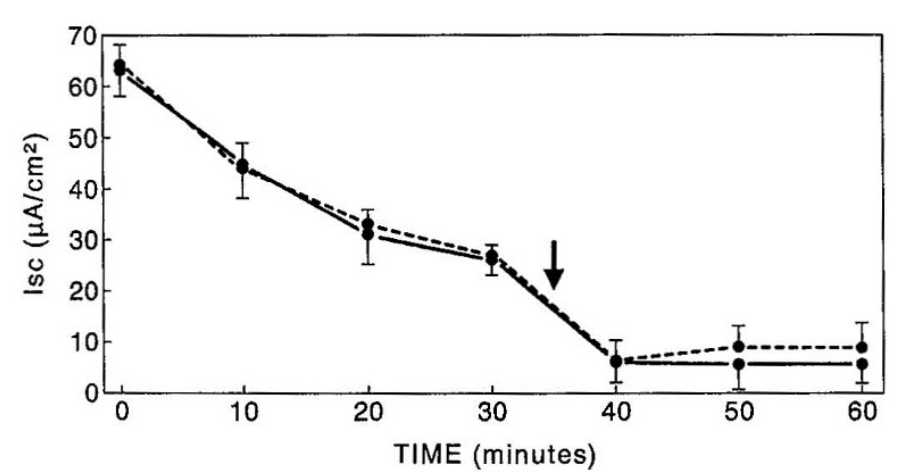

Figure 4. Effect of r-hGH withdrawal on r-hGH-induced decrease of Isc. Ileal mucosa was exposed to r-hGH for $35 \mathrm{~min}$ (arrow). The hormone was then rapidly removed (dotted line) and the electrical parameters were recorded during the next $25 \mathrm{~min}$. No significant difference was observed with tissue constantly exposed to r-hGH (continuous line) $(n=4)$.

Chloride dependency of $\mathbf{r}$-hGH effect. To test the hypothesis that in vitro $\mathrm{r}-\mathrm{hGH}$ action was related to $\mathrm{Cl}^{-}$movements, the addition of $\mathrm{r}-\mathrm{hGH}$ to ileal specimens was examined in $\mathrm{Cl}^{-}$-free buffer. Results are reported in Figure 5. The decrease in Isc induced by r-hGH was abolished in the absence of $\mathrm{Cl}^{-}$, thus indicating that the electrical effect of $r-h \mathrm{GH}$ was $\mathrm{Cl}^{-}$dependent.

Effects of r-hGH on secretagogue-induced changes in Isc. Active intestinal secretion can be induced by an increase in intracellular concentration of 1) cAMP, 2) cGMP, or 3) $\mathrm{Ca}^{2+}$. To test whether r-hGH also affects active intestinal secretion, the effects of the hormone on the secretory pattern induced by agonists of cAMP, cGMP, or $\mathrm{Ca}^{2+}$ were examined, as detailed under "Methods." Results are shown in Figure 6. r-hGH was able to reduce the secretory effects of all three mediators.

\section{DISCUSSION}

It has been previously reported that hypophysectomy causes a decrease in water and electrolyte absorption in the rat jejunum and this can be prevented by pretreatment with bovine GH (19). An intestinal proabsorptive effect has been previously reported in normal rats, receiving ovine $\mathrm{GH}$ by s.c. route (8).

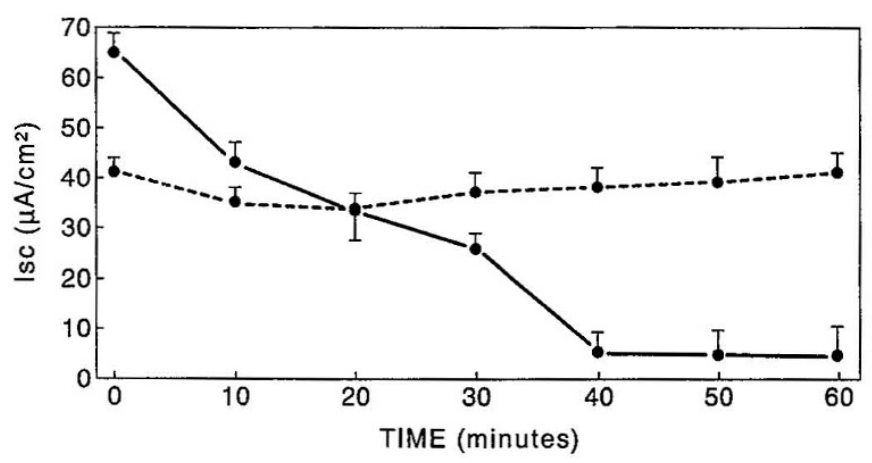

Figure 5. $\mathrm{Cl}^{-}$dependency of $\mathrm{r}-\mathrm{hGH}$-induced electrical effect. Ileal mucosa was exposed to r-hGH in standard Ringer's solution (continuous line) and in $\mathrm{Cl}^{-}$-free Ringer's solution (dotted line). In the absence of $\mathrm{Cl}^{-}$, the addition of $\mathrm{r}$-hGH did not induce electrical modifications. A significant difference in Isc basal values was also observed in the presence or absence of $\mathrm{Cl}^{-}(n=4)$.

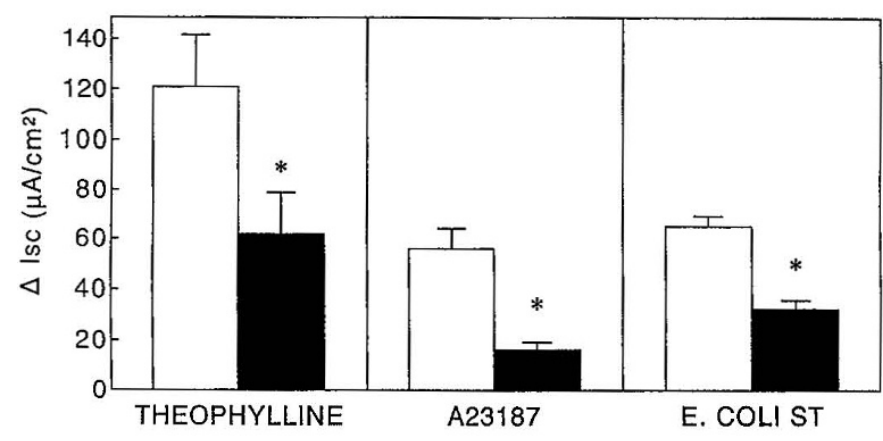

Figure 6. Peak increments in Isc produced by intestinal secretagogues in the absence (white columns) or in the presence (black columns) of $\mathrm{r}-\mathrm{hGH}$. All secretagogues were added $20 \mathrm{~min}$ after serosal addition of $\mathrm{r}-\mathrm{hGH}\left(4 \times 10^{-6}\right.$ $\mathrm{M})$, and Isc values were recorded in the following $60 \mathrm{~min}(n=8$ for each secretagogue tested). ${ }^{*} p<0.01$.

Our results demonstrate 1) that human recombinant DNAderived GH is able to rapidly promote intestinal absorption of water and electrolytes, 2) that this effect is, at least in part, related to a direct interaction between the hormone and the intestinal epithelium, and 3) that r-hGH is also capable of reducing active intestinal secretion induced by various mechanisms.

The first observation confirms and extends the previously reported proabsorptive effect of animal $\mathrm{GH}(8,19)$ to recombinant DNA-derived human GH. Furthermore, this work first shows that the effect on intestinal transport has a rapid onset, being observed within minutes from a single i.v. dose of $\mathrm{r}-\mathrm{hGH}$. The apparently transient nature of the proabsorptive effect in vivo is well explained by the half-life of $\mathrm{r}-\mathrm{hGH}$, which is reported to be $18 \mathrm{~min}$ after i.v. administration (20). It should be noted that the pharmacokinetic features of $\mathrm{r}-\mathrm{hGH}$ change, depending on the administration route, and more sustained concentrations may be achieved by intramuscular or s.c. compared with the i.v. administration (20). This could allow an absorptive effect of longer duration compared with that observed by i.v. administration of $\mathrm{r}-\mathrm{hGH}$, should alternative routes be used. The ileal proabsorptive effect consisted of an enhanced absorption of $\mathrm{H}_{2} \mathrm{O}, \mathrm{Na}^{+}, \mathrm{Cl}^{-}$, and $\mathrm{K}^{+}$, resembling that seen in the kidney of animals treated with $\mathrm{GH}$ (1).

The antinatriuretic effect of GH in the kidney is thought to be, at least in part, indirect and probably mediated by the activation of the renin-angiotensin system and by an increase of aldosterone (21). However, other evidence suggest a role for IGF-1 and even the possibility of a direct effect of GH has been proposed, because receptors for $\mathrm{GH}$ have been identified on renal tubular cells (1). The in vitro experiments gave us the opportunity to better characterize the intestinal effects of $\mathrm{r}-\mathrm{hGH}$.

The observed decrease of Isc in response to $\mathrm{r}-\mathrm{hGH}$ addition may be due either to an increase in net movement of an anion from mucosal to serosal compartment (increased absorption or decreased secretion) or an increase in net movement of a cation from serosal to mucosal compartment (decreased absorption or increased secretion). Several lines of evidence support the hypothesis that the $\mathrm{r}-\mathrm{hGH}$-induced decrease in Isc was related to a proabsorptive and/or antisecretory effect. First, GH has been known for several decades to cause fluid retention (1). Second, our data from in vivo perfusion studies clearly showed an 
intestinal proabsorptive effect after GH administration. It should be noted that such an effect was obtained in a range of hormone concentrations which are well below those previously administered to human volunteers (20). Third, the dependency on $\mathrm{Cl}^{-}$of the electrical response to r-hGH represents clear-cut evidence in favor of the antisecretory nature of the hormone effect.

Indeed, it is now known that $\mathrm{Cl}^{-}$secretion continues in the absence of externally applied forces (22), and it is responsible for lumen-negative electrical potential difference (23). The latter can be controlled by voltage clamp, generating a positive value of Isc. In fact, in our experiments performed in $\mathrm{Cl}^{-}$-free Ringer's solution, basal Isc values were lower than those obtained in normal $\mathrm{Cl}^{-}$-containing Ringer's solution. The loss of $\mathrm{GH}$ ability to induce Isc decrease in the absence of $\mathrm{Cl}^{-}$strongly suggests that r-hGH inhibits basal active $\mathrm{Cl}^{-}$secretion.

The in vitro experiments showed that the effect of $\mathrm{r}-\mathrm{hGH}$ was of direct type. A direct $\mathrm{GH}$-enterocyte interaction is consistent with the presence of GH specific receptors on the enterocytes (14). The effect of r-hGH was seen when it was added on the serosal, but not the mucosal, side; it was time- and dose-dependent, saturable, and not reversible (at least within the time frame of our experiment).

The time course of r-hGH, either in the in vivo and the in vitro experiments, showed a rapid onset of the effect. The in vitro effect was longer than that seen in vivo, which can be explained by the intervention of homeostatic mechanisms to balance an excessive fluid retention in the in vivo rat. The dose response represents the first evidence of such a feature of the effect of GH on fluid retention, because a clear dose response was not obtained in previous work describing the influence of animal GH on intestinal transport (19).

The lack of reversibility of r-hGH effect, upon its removal from the incubation medium, is not surprising, as it is well known that the interaction of growth factors with cell surface receptors involves their binding, the redistribution of hormone-receptor complex at the cell surface, and the internalization and degradation and/or recycling of hormone and/or receptor (24). Overall these data represent evidence of a direct role of $\mathrm{GH}$ in the regulation of the homeostasis of water and electrolytes at the intestinal level.

The capability of r-hGH to inhibit secretagogue-stimulated Isc was also investigated. r-hGH inhibited by about 50,48 , and $68 \%$ the Isc changes induced by theophylline, by ST and by $\mathrm{Ca}^{2+}$ ionophore A23187, respectively. This suggests that the mechanism r-hGH activity is relatively nonspecific. It is possible that the effect of $\mathrm{GH}$ is related to inhibition of basal, rather than to stimulated $\mathrm{Cl}^{-}$secretion. Indeed, at least for ST and $\mathrm{Ca}^{2+}$ ionophore, the final Isc values could be interpreted as the average of initial GH-induced decrease and subsequent secretagogue-induced increase.

Treatment strategies for secretory diarrhea include drugs that stimulate absorption, those that inhibit secretion, and those that have both effects (25). Our data suggest that r-hGH exerts a proabsorptive effect in vivo, stimulating water and ion absorption.

Data from the in vitro experiments indicate that the proabsorptive effect observed in vivo is related, at least in part, to the inhibition of basal electrogenic $\mathrm{Cl}^{-}$secretion. In most cases diarrhea is the result of both impaired absorption and enhanced secretion (26). Therefore, this work discloses a potential use of r-hGH as treatment of diarrhea. The lack of side effects, even by the i.v. administration (20), together with the availability of $\mathrm{r}-\mathrm{hGH}$, make it an attractive tool to be used in the treatment of protracted and/or severe diarrhea.

Acknowledgment. The authors are grateful to Stefano Guandalini for his invaluable suggestions.

\section{REFERENCES}

1. Ho KY, Kelly JJ 1991 Role of growth hormone in fluid homeostasis. Horm Res $36: 44-48$

2. Powell DW 1987 Intestinal water and electrolyte transport. In: Johnson LE (ed) Physiology of the Gastrointestinal Tract, 2nd Ed. Raven Press, New York, pp 1267-1305

3. Shulman DI, Hu CS, Ducklett G, Lavallee-Grey M 1992 Effects of short-term growth hormone therapy in rats undergoing $75 \%$ small intestinal resection. J Pediatr Gastroenterol Nutr 14:3-11

4. Ulshen MH, Dowling RH, Fuller CR, Zimmermann EM, Lund PK 1993 Enhanced growth of small bowel in transgenic mice overexpressing bovine growth hormone. Gastroenterology 104:973-980

5. Bruns MEH, Vollmer SS, Bruns DE, Overpeck JG 1983 Human growth hormone increases intestinal vitamin D dependent calcium binding protein in hypophysectomized rats. Endocrinology 113:1387-1392

6. Chipman JJ, Zerwekh J, Nicar M, Marks J, Pak CYC 1980 Effect of growth hormone administration: reciprocal changes in serum $1 \alpha, 25$-dihydroxyvitamin $\mathrm{D}$ and intestinal calcium absorption. J Clin Endocrinol Metab 51:321-324

7. Kasanuki J, Makino H, Matsushima Y, Kanatsuka A, Miyahira M, Tokumasa Y, Kumagai A 1981 Effect of hypophysectomy and growth hormone administration on somatostatin and gastrin content in the stomach of rats. Endocrinol Jpn 28:257-260

8. Mainoya JR 1982 Influence of ovine growth hormone on water and $\mathrm{NaCl}$ absorption by the rat proximal jejunum and distal ileum. Comp Biochem Physiol 7:477-479

9. Daughaday WH, Hall K, Raben MS, Salmon WD, Van den Brande JL, Van Wyk JJ 1972 Somatomedin: proposed designation for sulphation factor. Nature 235:107

10. Rudd BT 1991 Growth, growth hormone and the somatomedins: a historical perspective and current concepts. Ann Clin Biochem 28:542-555

11. Guler HP, Schmid C, Zapf J, Froesch RE 1989 Effects of recombinant insulin-like growth factor $I$ on insulin secretion and renal function in normal human subjects. Proc Natl Acad Sci USA 86:2868-2872

12. Moller J, Jorgensen JOL, Moller N, Hansen KW, Pedersen EB, Christiansen JS 1991 Expansion of extracellular volume and suppression of atrial natriuretic peptide after growth hormone administration in normal man. J Clin Endocrinol Metab 72:768-772

13. Guarino A, Tarallo L, Berni Canani R, Nocerino A, Iafusco M, Raimondi F, Rubino A 1992 Comparative effects of atrial natriuretic peptide and $E$. coli heat-stable toxin on rat intestinal transport. J Pediatr Gastroenterol Nutr 15:105-111

14. Lobie PE, Breipohl W, Waters MJ 1990 Growth hormone receptor expression in the rat gastrointestinal tract. Endocrinology 126:299-306

15. De Curtis M, Guandalini S, Fasano A, Saitta F, Ciccimarra F 1989 Diarrhea in jaundice neonates treated with phototherapy: role of intestinal secretion. Arch Dis Child 64:1161-1164

16. Field M, Fromm D, McColl I 1971 Ion transport in rabbit ileal mucosa. I. Na and Cl fluxes and short-circuit current. Am J Physiol 220:1388-1396

17. Field M, Rao MC, Chang EB 1989 Intestinal electrolyte transport and diarrheal disease. N Engl J Med 321:800-806

18. Guandalini S, Fasano A, Rao MC, Ferola A, Migliavacca M, Marchesano G, Rubino A 1984 Effects of loperamide on ion transport. J Pediatr Gastroenterol Nutr 3:593-601

19. Mainoya JR 1975 Effects of bovine growth hormone, human placental lactogen and ovine prolactin on intestinal fluid and ion transport in the rat. Endocrinology 96:1975-1980

20. Zeisel HJ, Petrikowski WV, Wais U 1992 Pharmacokinetics and short-term metabolic effects of mammalian cell-derived biosyntethic human growth hormone in man. Horm Res 37:5-13

21. Ho KY, Weissberger AJ 1990 The antinatriuretic action of biosynthetic human growth hormone in man involves activation of the renin-angiotensin system. Metabolism 39:133-137

22. Frizzell RA, Field M, Schultz SG 1979 Sodium-coupled chloride transport by epithelial tissue. Am J Physiol 236:F1-F8

23. Halm DR, Frizzell RA. Intestinal chloride secretion. In: Lebenthal E, Duffey M (eds) Textbook of Secretory Diarrhea. Raven Press, New York, pp 47-58

24. Ilondo MM, Vanderschueren-Lodeweyekx M, Courtoy PJ, De Meyts P 1992 Cellular processing of growth hormone in IM-9 cells: evidence for exocytosis of internalized hormone. Endocrinology 130:2037-2044

25. Donowitz M, Levine S, Watson A 1990 New drug treatments for diarrhoea. Ann Intern Med 228(suppl 1):155-163

26. Booth IW, McNeish AS 1993 Mechanisms of diarrhoea. Baillieres Clin Gastroenterol 7:215-242 